\title{
Paced Ventricular Single Beat QRS Duration
}

National Cancer Institute

\section{Source}

National Cancer Institute. Paced Ventricular Single Beat QRS Duration. NCI Thesaurus.

Code C117782.

An electrocardiographic interval measured from the onset of the paced QRS complex to the offset of the QRS complex of a single beat utilizing one or more leads. (CDISC) 